\title{
Combination of CDK4/6 and mTOR Inhibitors Suppressed Doxorubicin-resistant Osteosarcoma in a Patient-derived Orthotopic Xenograft Mouse Model: A Translatable Strategy for Recalcitrant Disease
}

\author{
HIROMICHI OSHIRO ${ }^{1,2,3}$, YASUNORI TOME ${ }^{3}$, KENTARO MIYAKE $^{1,2}$, TAKASHI HIGUCHI ${ }^{1,2}$, \\ NORIHIKO SUGISAWA ${ }^{1,2}$, FUMINORI KANAYA ${ }^{3}$, KOTARO NISHIDA ${ }^{3}$ and ROBERT M. HOFFMAN ${ }^{1,2}$ \\ ${ }^{1}$ AntiCancer Inc., San Diego, CA, U.S.A.; \\ ${ }^{2}$ Department of Surgery, University of California, San Diego, CA, U.S.A.; \\ ${ }^{3}$ Department of Orthopedic Surgery, Graduate School of Medicine, University of the Ryukyus, Okinawa, Japan
}

\begin{abstract}
Background: Osteosarcoma is the most frequent malignant bone neoplasm. The efficacy of combination therapy of a cyclin-dependent kinase 4/6 (CDK4/6) inhibitor and a mammalian-target-of-rapamycin (mTOR) inhibitor was previously reported in several cancer types. In the present study, we evaluated the efficacy of a combination of palbociclib (CDK $4 / 6$ inhibitor) and everolimus (mTOR inhibitor) on an osteosarcoma patient-derived orthotopic xenograft (PDOX) mouse model. Materials and Methods: osteosarcoma PDOX mouse models were randomized into five treatment groups of seven mice each: Group 1, untreated control; group 2, doxorubicin treatment; group 3, palbociclib treatment; group 4, everolimus treatment; group 5, palbociclib-everolimus combination treatment. Treatment duration was 2 weeks. Results: The palbociclib-everolimus combination reduced the tumorvolume ratio in the osteosarcoma PDOX mouse model compared with the control and doxorubicin $(p=0.018)$. Everolimus alone also inhibited osteosarcoma PDOX growth compared to the control ( $p=0.04)$, but less than the combination. Palbociclib alone and doxorubicin were ineffective. There were no significant body-weight losses in any group. Only the
\end{abstract}

This article is freely accessible online.

Correspondence to: Robert M. Hoffman, Ph.D., AntiCancer Inc., 7917 Ostrow Street, San Diego, CA, 92122, U.S.A. E-mail: all@anticancer.com and Yasunori Tome, MD, Ph.D., Department of Orthopedic Surgery, Graduate School of Medicine, University of the Ryukyus, 207 Uehara, Nishihara-cho, Nakagami-gun, Okinawa, 903-0215, Japan. E-mail: yastome@med.u-ryukyu.ac.jp

Key Words: Osteosarcoma, CDK4/6 inhibitor, palbociclib, mTOR inhibitor, everolimus, patient-derived orthotopic xenograft, PDOX, cell cycle. palbociclib-everolimus combination induced extensive tumor necrosis observed histopathologically. Conclusion: The present study demonstrated that the combination of CDK4/6 and mTOR inhibitors can be a translatable approach for doxorubicinresistant osteosarcoma in the clinic.

Osteosarcoma is the most frequent and malignant primary bone sarcoma in children and adolescents. Neoadjuvant and adjuvant chemotherapy are first-line treatment of osteosarcoma combined with surgery. First-line chemotherapy includes doxorubicin, methotrexate, and cisplatinum. However, second-line chemotherapy for osteosarcoma has limited efficacy and thus drug-resistant osteosarcoma is a recalcitrant disease $(1,2)$. Therefore, new therapeutic strategies of systemic therapy are necessary for second or later lines of treatment for osteosarcoma.

Cyclin-dependent kinase 4/6 (CDK4/6) and mammalian target of rapamycin (mTOR) inhibitors are candidates for second-line treatment of osteosarcoma (3-5). The CDK4/6 inhibitor palbociclib was approved as a systemic therapy for advanced breast cancer (6). Palbociclib inhibits CDK4/6 from forming a complex with cyclin $\mathrm{D}$, thereby preventing the phosphorylation of retinoblastoma protein and causing cellcycle arrest $(7,8)$. An mTOR inhibitor, everolimus, was approved as a therapeutic for advanced breast and renal-cell cancer $(9,10)$. There are several reports that the combination of CDK4/6 and mTOR inhibitors had efficacy on glioma, breast cancer, and cholangiocarcinoma (3-5). However, there are no reports on the efficacy of a combination of CDK4/6 and mTOR inhibitors on osteosarcoma to our knowledge thus far.

The aim of the present study was to evaluate the efficacy of the palbociclib-everolimus (PAL-EVE) combination on a clinically-relevant osteosarcoma patient-derived orthotopic xenograft (PDOX) mouse model, for potential translation to the clinic (11-16). 


\section{Materials and Methods}

Mice. Athymic nu/nu nude mice (AntiCancer Inc., San Diego, CA, USA), 4-6 weeks old, were used in the present study. Mouse housing, surgical procedures, imaging and sacrifice were performed as described in previous publications (17-20). An AntiCancer Institutional Animal Care and Use Committee-approved protocol was used for all of the studies according to the procedures and principles summarized in the National Institutes of Health Guide for the Care and Use of Laboratory Animals, eighth edition, under Public Health Service Approved Animal Welfare Assurance Number A3873-1 (21).

Establishment of the osteosarcoma PDOX mouse model by surgical orthotopic implantation (SOI). A 16-year-old female patient with high-grade osteosarcoma of the left distal femur underwent neoadjuvant chemotherapy including doxorubicin and surgery with replacement of the distal femur. One year after surgery, bilateral pulmonary metastases developed (22). Informed consent from the patient and her parents for use of tissue was previously acquired under an Institutional Review Board-approved protocol of University of California, Los Angeles (IRB \#10-001857).

A primary osteosarcoma tumor from the left distal femur of the patient was previously established subcutaneously on the back of nude mice $(22,23)$. The subcutaneously-grown tumors were resected and small fragments were made from them. After nude mice were anesthetized with a ketamine solution, a 10-mm skin incision was made on the lateral side of the right knee. The vastus lateralis muscle was opened and the biceps femoris muscle was split to reach the lateral distal femur. The lateral condyle of the femur was resected with scissors to make a cavity for implantation of the tumor fragment. A single tumor fragment was implanted orthotopically into the cavity of the lateral condyle to establish a PDOX mouse model. The skin was subsequently closed with a 6-0 suture. Please see our previous publications for further details of the surgical orthotopic implantation of osteosarcoma $(22,23)$.

Therapeutic study design in the osteosarcoma PDOX model. Five groups of seven mice each were randomly assigned from the osteosarcoma PDOX mouse model: Group 1, control treated weekly with phosphate-buffered saline (i.p.); group 2, treated weekly with $3 \mathrm{mg} / \mathrm{kg}$ doxorubicin (DOX) (i.p.); group 3, treated daily with 75 $\mathrm{mg} / \mathrm{kg}$ palbociclib (PAL) by oral gavage; group 4 , treated with 5 $\mathrm{mg} / \mathrm{kg}$ everolimus (EVE) daily by oral gavage; group 5, treated daily with both $75 \mathrm{mg} / \mathrm{kg}$ PAL and $5 \mathrm{mg} / \mathrm{kg}$ EVE. The therapeutic schedule for the osteosarcoma PDOX mouse model is shown in Figure 1. Treatment duration was for 14 days. The therapeutic doses were determined from previous studies (24-26).

The long and short diameters of the tumor were measured with calipers and body weight was monitored with a digital balance twice a week. Tumor volume was calculated with the following formula: Tumor volume $\left(\mathrm{mm}^{3}\right)=$ long diameter $(\mathrm{mm}) \times$ short diameter $(\mathrm{mm})$ $\times$ short diameter $(\mathrm{mm}) \times 1 / 2$. The tumor volume ratio was calculated as the tumor volume at each time point relative to the volume of the initial tumor.

Histopathological examination. Resected tumor specimens were fixed in $10 \%$ formalin and embedded in paraffin before sectioning and staining. Tissue sections $(5 \mu \mathrm{m})$ were deparaffinized in xylene and rehydrated in an ethanolic series. Hematoxylin and eosin staining was performed with standard protocols (15).

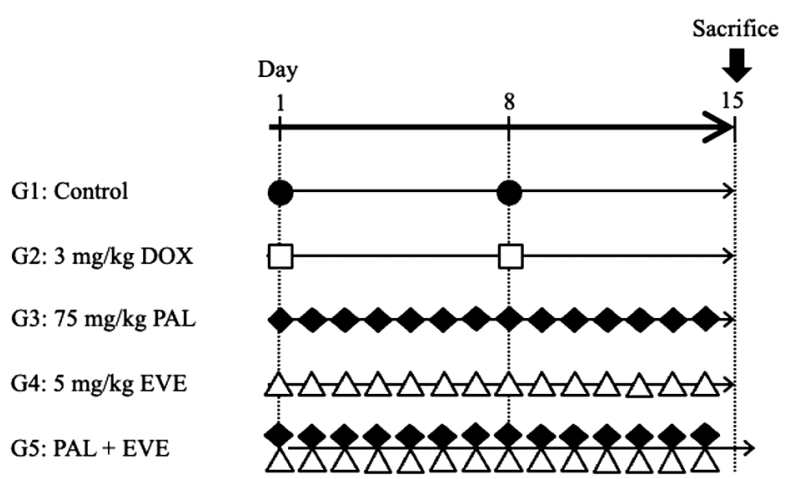

Figure 1. Therapeutic schema for an osteosarcoma patient-derived orthotopic xenograft mouse model. Treatment started on day 1 and ended on day 15. Group 1, untreated control with PBS i.p.; group 2, treated with $3 \mathrm{mg} / \mathrm{kg}$ doxorubicin (DOX) i.p. weekly; group 3, treated daily with $75 \mathrm{mg} / \mathrm{kg}$ palbociclib (PAL) by oral gavage; group 4, treated daily with $3 \mathrm{mg} / \mathrm{kg}$ everolimus (EVE) by oral gavage; group 5 , treated daily with both $75 \mathrm{mg} / \mathrm{kg} P A L$ and $3 \mathrm{mg} / \mathrm{kg}$ EVE by oral gavage.

Statistical analysis. JMP version 13.0 (SAS institute Inc., Cary, NC, USA) was used for statistical analyses. The Steel-Dwass test for tumor- volume ratio and the Tukey-Kramer test for body-weight ratio were used for analysis. Line graphs or bar graphs demonstrate average, and error bars show \pm standard deviation. A probability value of $p \leq 0.05$ was considered to indicate a statistically-significant difference.

\section{Results}

Efficacy of the combination of palbociclib (PAL) and everolimus (EVE) on the osteosarcoma PDOX mouse model. Representative photographs of treated mice and tumors resected after treatment are shown in Figure 2. The tumor-volume ratio from the beginning of treatment until the end of treatment is shown in Figure 3.

Tumor-volume ratios at the end of the study were $6.42 \pm 1.20$ for the untreated-control group; $4.96 \pm 1.39$ for the doxorubicin-treated group; $4.64 \pm 1.88$ for the palbociclibtreated group; $3.34 \pm 1.23$ for the everolimus-treated group; and $2.32 \pm 0.52$ for the PAL-EVE combination-treated group.

The mice treated with doxorubicin and palbociclib alone showed no significant difference in tumor growth compared with the untreated-control group $(p=0.31$ and 0.38 , respectively). However, the PAL-EVE combination arrested tumor growth significantly compared with untreated-control and doxorubicin-treated mice $(p=0.018)$. Everolimus alone also inhibited tumor growth significantly compared with the control ( $p=0.04$ ) (Figures 2 and 3).

Histopathology of treated and untreated tumors in the osteosarcoma PDOX mouse model. The untreated-control tumors had a high density of pleomorphic and spindle-shaped cancer cells. as did those in the tumors treated with single 


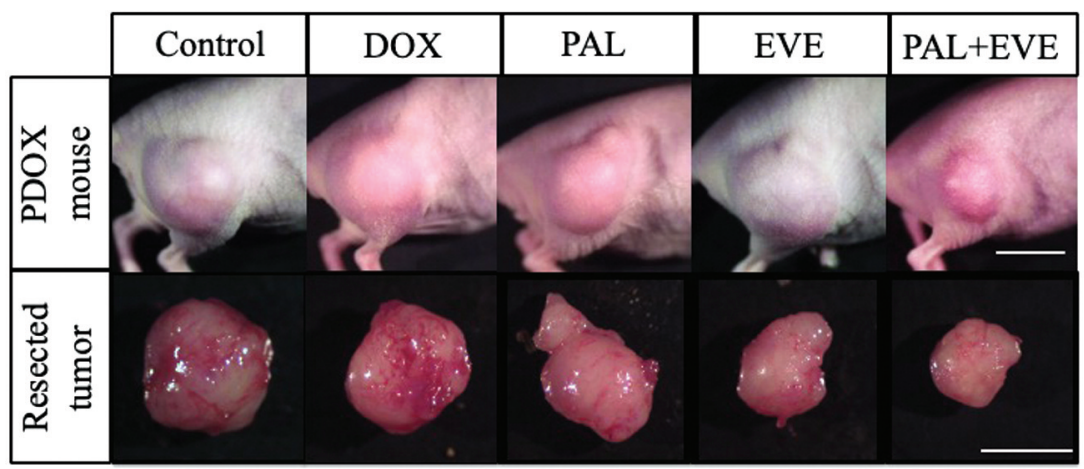

Figure 2. Representative photographs of tumors in situ and resected tumors from osteosarcoma patient-derived orthotopic xenograft (PDOX) mouse models: untreated (control); or treated with $3 \mathrm{mg} / \mathrm{kg}$ doxorubicin (DOX) i.p. weekly; or treated daily with $75 \mathrm{mg} / \mathrm{kg}$ palbociclib (PAL); or treated daily with $3 \mathrm{mg} / \mathrm{kg}$ everolimus (EVE); or treated daily with both $75 \mathrm{mg} / \mathrm{kg}$ PAL and $3 \mathrm{mg} / \mathrm{kg}$ EVE. The PAL-EVE combination demonstrated the greatest efficacy against the osteosarcoma PDOX models. Scale bars are $10 \mathrm{~mm}$.

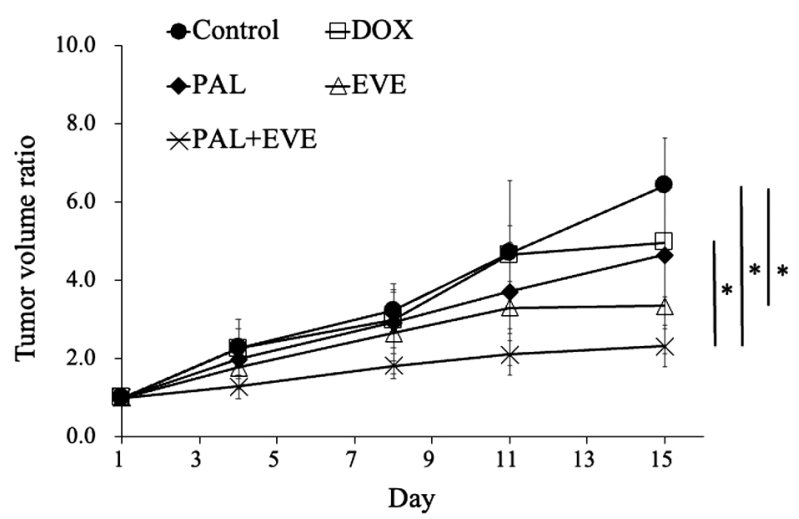

Figure 3. Therapeutic efficacy against osteosarcoma patient-derived orthotopic xenograft mouse models: untreated (control); or treated with $3 \mathrm{mg} / \mathrm{kg}$ doxorubicin (DOX) i.p. weekly; or treated daily with $75 \mathrm{mg} / \mathrm{kg}$ palbociclib (PAL); or treated daily $3 \mathrm{mg} / \mathrm{kg}$ everolimus (EVE); or treated daily with both $75 \mathrm{mg} / \mathrm{kg} P A L$ and $3 \mathrm{mg} / \mathrm{kg}$ EVE. The mean tumor-volume ratios, i.e., tumor volume at each time point relative to the initial tumor volume, are shown with standard deviation. The Steel-Dwass test was used for statistical analysis. *Significant different at $p<0.05$.

agents. However, the PAL-EVE combination resulted in a lower density of cancer cells and had more necrosis compared with all other groups (Figure 4).

Body weight in the osteosarcoma PDOX mouse model Animal deaths were not observed in any group. Body weight on day 15 relative to body weight at the beginning of the study did not significantly differ among groups. Moreover, there was no body-weight loss in any group (Figure 5).

\section{Discussion}

The present study demonstrated that palbociclib alone did not suppress tumor growth significantly compared with other treatments on the osteosarcoma PDOX model. However, the

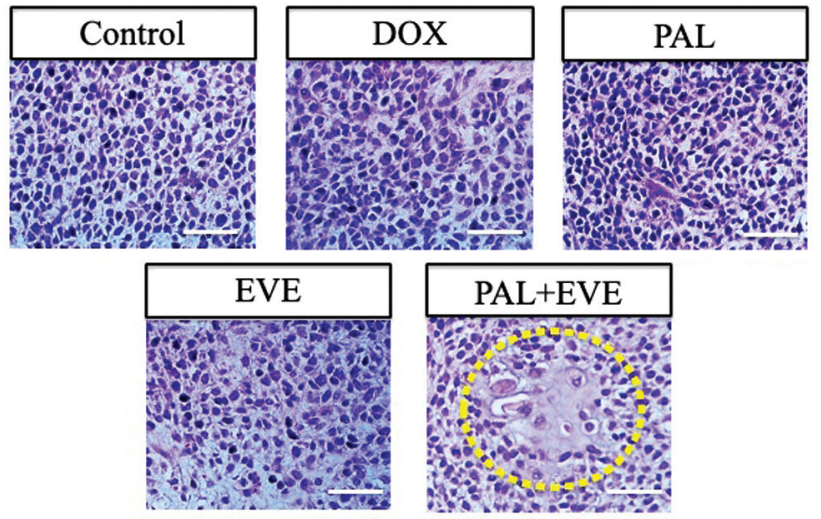

Figure 4. Therapeutic efficacy as shown by histopathology of the osteosarcoma patient-derived orthotopic xenograft mouse models (hematoxylin and eosin staining. Mice were treated as follows: untreated (control); or treated with $3 \mathrm{mg} / \mathrm{kg}$ doxorubicin (DOX) i.p. weekly; treated daily with $75 \mathrm{mg} / \mathrm{kg}$ palbociclib (PAL); or treated daily with $3 \mathrm{mg} / \mathrm{kg}$ everolimus (EVE); or treated daily with both $75 \mathrm{mg} / \mathrm{kg} P A L$ and $3 \mathrm{mg} / \mathrm{kg}$ EVE. The yellow circle indicates the area of necrosis. Scale bars are $100 \mu \mathrm{m}$.

PAL-EVE combination had significant efficacy in the osteosarcoma PDOX mouse model compared with the control and DOX-treated groups. The PAL-EVE combination also resulted in extensive tumor necrosis, as shown by histopathology. No tumor necrosis was found in mice from the other groups. The PAL-EVE combination did not result in treatment-related animal deaths or body-weight loss, which indicates the combination therapy was not toxic, at least at the gross level.

CDK4 was found to be an effective therapeutic target in breast cancer $(6,27)$. There are some reports of over-expression of CDK4 in osteosarcoma, related to distal metastases and poor prognosis in clinical settings $(28,29)$. The inhibition of CDK4 in previous studies demonstrated that it is possible to reduce cell proliferation and induce apoptosis via cell-cycle arrest in vitro and in vivo of breast cancer, melanoma and osteosarcoma (29- 


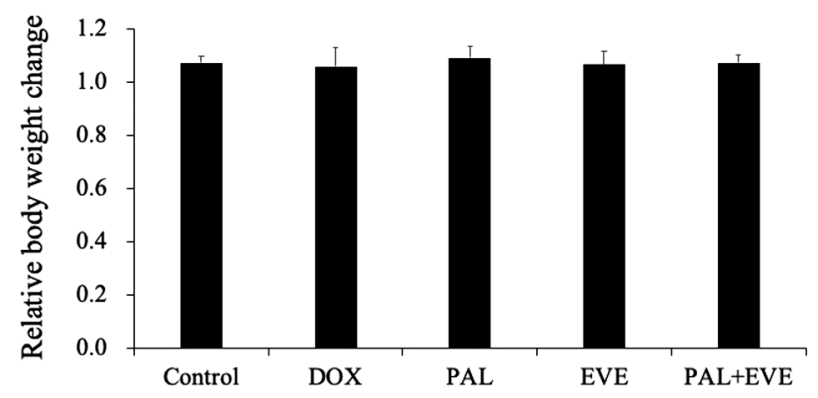

Figure 5. Effect of treatment on body weight in the osteosarcoma patientderived orthotopic xenograft mouse models. Data are the ratio of the body weight of mice on day 15 relative to the initial body weight. The Tukey-Kramer test was used for statistical analysis; there were no significant differences in body weight between groups.

31). CDK4/6 inhibitors were predicted to have efficacy on osteosarcoma based on these findings. However, the present study showed that monotherapy with the CDK 4/6 inhibitor palbociclib did not inihibit tumor growth significantly on the osteosarcoma PDOX model, compared with other groups.

The combination of a CDK4/6 inhibitor and an mTOR inhibitor was shown to inhibit growth in vitro and in vivo of glioblastoma, malignant pleural mesothelioma, and triplenegative breast cancer (32-34). CDK4/6 inhibition demonstrated down-regulation of down-stream mediators of the mTOR pathway and up-regulation of the phosphatidylinositol-4,5bisphosphate 3-kinase/AKT serine/threonine kinase-1/mTOR pathways in several cancer types (32-34). Therefore, we combined in the present study, a CDK4/6 inhibitor with an mTOR inhibitor, in order to overcome resistance to monotherapy with a CDK4/6 inhibitor.

The mTOR inhibitor everolimus was approved as a treatment for advanced breast and renal cell cancer $(9,10)$. Furthermore, the mTOR-inhibitor rapamycin was reported to down-regulate cyclin D and induce cell-cycle arrest (35). From these findings, a CDK4/6 inhibitor combined with an mTOR inhibitor was predicted to have strong efficacy. In the present study, monotherapy with a CDK4/6 inhibitor did not significantly inhibit osteosarcoma PDOX growth. However, the PAL-EVE combination inhibited osteosarcoma PDOX growth significantlycompared with the untreated control and treatment with doxorubicin. These results suggest that a CDK4/6 inhibitor and an mTOR inhibitor, may have a synergistic effect on induction of cell-cycle arrest.

The main limitation of our study is that expression of CDK4/6 and mTOR in the osteosarcoma PDOX mouse model was not determined. There are several reports that a CDK 4/6 inhibitor demonstrated up-regulation of phosphatidylinositol4,5-bisphosphate 3-kinase/AKT serine/threonine kinase$1 /$ mTOR pathways in several cancers (32-35). Therefore, combined inhibition of the CDK 4/6 and mTOR pathways has a possibility as a new therapeutic strategy.
The present study showed that the combination of CDK4/6 and mTOR inhibitors had efficacy in an osteosarcoma PDOX mouse model. Future studies will determine how the level of CDK4/6 and mTOR pathway members affect the response to the PAL-EVE combination in the osteosarcoma PDOX mouse model.

The present study demonstrated that DOX and PAL alone had no efficacy while the PAL-EVE combination had efficacy against a clinically-relevant, doxorubicin-resistant osteosarcoma PDOX mouse model. It should be noted that both the osteosarcoma patient and the osteosarcoma PDOX model derived from the patient were resistant to doxorubicin. The present study suggests the potential clinical translation of combined inhibition of CDK4/6 and mTOR for second-line therapy of osteosarcoma. The present study, along with our recent studies (36-40), demonstrate the power of the PDOX model to identify effective therapy for osteosarcoma.

\section{Conflicts of Interest}

None declared.

\section{Authors' Contributions}

HO, YT, and RMH wrote this article. YT, SRS, and RMH contributed to the final version of the article. HO, KM, TH, NS, and SRS conceived and planned the experiments. HO performed the experiments. FK and KN supervised this study.

\section{Acknowledgements}

This article is dedicated to the memory of AR Moossa MD, Sun Lee, MD, Professor Li Jia Xi, and Masaki Kitajima, MD.

\section{References}

1 Isakoff MS, Bielack SS, Meltzer P and Gorlick R: Osteosarcoma: Current treatment and a collaborative pathway to success. J Clin Oncol 33(27): 3029-3035, 2015. PMID: 26304877. DOI: 10.1200/JCO.2014.59.4895

2 Seto T, Song MN, Trieu M, Yu J, Sidhu M, Liu CM, Sam D and Pan M: Real-world experiences with pazopanib in patients with advanced soft tissue and bone sarcoma in Northern California. Med Sci (Basel) 7(3): 48, 2019. PMID: 30889920. DOI: 10.3390/medsci7030048

3 Asby DJ, Killick-Cole CL, Boulter LJ, Singleton WG, Asby CA, Wyatt MJ, Barua NU, Bienemann AS and Gill SS: Combined use of CDK4/6 and mTOR inhibitors induce synergistic growth arrest of diffuse intrinsic pontine glioma cells via mutual downregulation of mTORC1 activity. Cancer Manag Res 10: 3483-3500, 2018. PMID: 30254491. DOI: 10.2147/CMAR.S167095

4 Song X, Liu X, Wang H, Wang J, Qiao Y, Cigliano A, Utpatel K, Ribback S, Pilo MG, Serra M, Gordan JD, Che L, Zhang S, Cossu A, Porcu A, Pascale RM, Dombrowski F, Hu H, Calvisi DF, Evert $\mathrm{M}$ and Chen X: Combined CDK4/6 and Pan-mTOR inhibition is synergistic against intrahepatic cholangiocarcinoma. Clin Cancer Res 25(1): 403-413, 2019. PMID: 30084835. DOI: 10.1158/10780432.CCR-18-0284 
5 Michaloglou C, Crafter C, Siersbaek R, Delpuech O, Curwen JO, Carnevalli LS, Staniszewska AD, Polanska UM, Cheraghchi-Bashi A, Lawson M, Chernukhin I, McEwen R, Carroll JS and Cosulich SC: Combined inhibition of mTOR and CDK4/6 is required for optimal blockade of E2F function and long-term growth inhibition in estrogen receptor-positive breast cancer. Mol Cancer Ther 17(5): 908-920, 2018. PMID: 29483206. DOI: 10.1158/1535-7163.MCT-17-0537

6 Finn RS, Martin M, Rugo HS, Jones S, Im SA, Gelmon K, Harbeck N, Lipatov ON, Walshe JM, Moulder S, Gauthier E, Lu DR, Randolph S, Diéras V and Slamon DJ: Palbociclib and letrozole in advanced breast cancer. N Engl J Med 375(20): 19251936, 2016. PMID: 27959613. DOI: 10.1056/NEJMoa1607303

7 Harbour JW, Luo RX, Dei Santi A, Postigo AA and Dean DC: $\mathrm{Cdk}$ phosphorylation triggers sequential intramolecular interactions that progressively block $\mathrm{Rb}$ functions as cells move through G1. Cell 98(6): 859-869, 1999. PMID: 10499802. DOI: 10.1016/s0092-8674(00)81519-6

8 Lundberg AS and Weinberg RA: Functional inactivation of the retinoblastoma protein requires sequential modification by at least two distinct cyclin-cdk complexes. Mol Cell Biol 18(2): 753-761, 1998. PMID: 9447971 . DOI: 10.1128/MCB.18.2.753

9 Yardley DA, Noguchi S, Pritchard KI, Burris HA 3rd, Baselga J, Gnant M, Hortobagyi GN, Campone M, Pistilli B, Piccart M, Melichar B, Petrakova K, Arena FP, Erdkamp F, Harb WA, Feng W, Cahana A, Taran T, Lebwohl D and Rugo HS: Everolimus plus exemestane in postmenopausal patients with $\mathrm{HR}(+)$ breast cancer: BOLERO-2 final progression-free survival analysis. Adv Ther 30(10): 870-884, 2013. PMID: 24158787. DOI: 10.1007/s12325-013-0060-1

10 Motzer RJ, Escudier B, Oudard S, Hutson TE, Porta C, Bracarda S, Grünwald V, Thompson JA, Figlin RA, Hollaender N, Urbanowitz G, Berg WJ, Kay A, Lebwohl D, Ravaud A and RECORD-1 Study Group: Efficacy of everolimus in advanced renal cell carcinoma: a double-blind, randomised, placebocontrolled phase III trial. Lancet 372(9637): 449-456, 2008. PMID: 18653228. DOI: 10.1016/S0140-6736(08)61039-9

11 Kiyuna T, Murakami T, Tome Y, Igarashi K, Kawaguchi K, Russell T, Eckardt MA, Crompton J, Singh A, Bernthal N, Bukata S, Federman N, Kanaya F, Eilber FC and Hoffman RM: Labeling the stroma of a patient-derived orthotopic xenograft (PDOX) mouse model of undifferentiated pleomorphic soft-tissue sarcoma with red fluorescent protein for rapid non-invasive imaging for drug screening. J Cell Biochem 118(2): 361-365, 2017. PMID: 27357060. DOI: $10.1002 /$ jcb. 25643

12 Hiroshima Y, Zhao M, Zhang Y, Zhang N, Maawy A, Murakami T, Mii S, Uehara F, Yamamoto M, Miwa S, Yano S, Momiyama M, Mori R, Matsuyama R, Chishima T, Tanaka K, Ichikawa Y, Bouvet M, Endo I and Hoffman RM: Tumor-targeting Salmonella typhimurium A1-R arrests a chemo-resistant patient soft-tissue sarcoma in nude mice. PLoS One 10(8): e0134324, 2015. PMID: 26237416. DOI: 10.1371 /journal.pone. 0134324

13 Murakami T, DeLong J, Eilber FC, Zhao M, Zhang Y, Zhang N, Singh A, Russell T, Deng S, Reynoso J, Quan C, Hiroshima Y, Matsuyama R, Chishima T, Tanaka K, Bouvet M, Chawla S, Endo I and Hoffman RM: Tumor-targeting Salmonella typhimurium A1$\mathrm{R}$ in combination with doxorubicin eradicate soft tissue sarcoma in a patient-derived orthotopic xenograft (PDOX) model. Oncotarget 7(11): 12783-12790, 2016. PMID: 26859573. DOI: 10.18632 /oncotarget.7226

14 Miyake K, Murakami T, Kiyuna T, Igarashi K, Kawaguchi K, Miyake M, Li Y, Nelson SD, Dry SM, Bouvet M, Elliott IA, Russell TA, Singh AS, Eckardt MA, Hiroshima Y, Momiyama M,
Matsuyama R, Chishima T, Endo I, Eilber FC and Hoffman RM: The combination of temozolomide-irinotecan regresses a doxorubicin-resistant patient-derived orthotopic xenograft (PDOX) nude-mouse model of recurrent Ewing's sarcoma with a FUS-ERG fusion and $C D K N 2 A$ deletion: Direction for third-line patient therapy. Oncotarget 8(61): 103129-103136, 2017. PMID: 29262551. DOI: $10.18632 /$ oncotarget.20789

15 Oshiro H, Tome Y, Kiyuna T, Miyake K, Kawaguchi K, Higuchi T, Miyake M, Zang Z, Razmjooei S, Barangi M, Wangsiricharoen S, Nelson SD, Li Y, Bouvet M, Singh SR, Kanaya F and Hoffman RM: Temozolomide targets and arrests a doxorubicin-resistant follicular dendritic-cell sarcoma patient-derived orthotopic xenograft mouse model. Tissue Cell 58: 17-23, 2019. PMID: 31133242. DOI: 10.1016/j.tice.2019.04.002

16 Oshiro H, Kiyuna T, Tome Y, Miyake K, Kawaguchi K, Higuchi T, Miyake M, Zhang Z, Razmjooei S, Barangi M, Wangsiricharoen S, Nelson SD, Li Y, Bouvet M, Singh SR, Kanaya F and Hoffman RM: Detection of metastasis in a patient-derived orthotopic xenograft (PDOX) model of undifferentiated pleomorphic sarcoma with red fluorescent protein. Anticancer Res 39(1): 81-85, 2019. PMID: 30591443. DOI: 10.21873/anticanres.13082

17 Igarashi K, Kawaguchi K, Kiyuna T, Miyake K, Miyaki M, Yamamoto N, Hayashi K, Kimura H, Miwa S, Higuchi T, Singh AS, Chmielowski B, Nelson SD, Russell TA, Eckardt MA, Dry SM, Li Y, Singh SR, Chawla SP, Eilber FC, Tsuchiya H and Hoffman RM: Metabolic targeting with recombinant methioninase combined with palbociclib regresses a doxorubicin-resistant dedifferentiated liposarcoma. Biochem Biophys Res Commun 506(4): 912-917, 2018. PMID: 30392912. DOI: 10.1016/j.bbrc.2018.10.119

18 Miyake K, Kiyuna T, Miyake M, Zhao M, Wangsiricharoen S, Kawaguchi K, Zhang Z, Higuchi T, Razmjooei S, Li Y, Nelson SD, Russell T, Singh A, Murakami T, Hiroshima Y, Momiyama M, Matsuyama R, Chishima T, Singh SR, Chawla SP, Eilber FC, Endo I and Hoffman RM: Tumor-targeting Salmonella typhimurium A1-R overcomes partial carboplatinum-resistance of a cancer of unknown primary (CUP). Tissue Cell 54: 144-149, 2018. PMID: 30309504. DOI: 10.1016/j.tice.2018.09.001

19 Kawaguchi K, Higuchi T, Li S, Han Q, Tan Y, Igarashi K, Zhao M, Miyake K, Kiyuna T, Miyake M, Ohshiro H, Sugisawa N, Zhang Z, Razmjooei S, Wangsiricharoen S, Chmielowski B, Nelson SD, Russell TA, Dry SM, Li Y, Eckardt MA, Singh AS, Singh SR, Eilber FC, Unno M and Hoffman RM: Combination therapy of tumor-targeting Salmonella typhimurium A1-R and oral recombinant methioninase regresses a BRAF-V600E-negative melanoma. Biochem Biophys Res Commun 503(4): 3086-3092, 2018. PMID: 30166061. DOI: 10.1016/j.bbrc.2018.08.097

20 Higuchi T, Kawaguchi K, Miyake K, Han Q, Tan Y, Oshiro H, Sugisawa N, Zhang Z, Razmjooei S, Yamamoto N, Hayashi K, Kimura H, Miwa S, Igarashi K, Chawla SP, Singh AS, Eilber FC, Singh SR, Tsuchiya $\mathrm{H}$ and Hoffman RM: Oral recombinant methioninase combined with caffeine and doxorubicin induced regression of a doxorubicin-resistant Synovial sarcoma in a PDOX mouse model. Anticancer Res 38(10): 5639-5644, 2018. PMID: 30275182. DOI: 10.21873/anticanres.12899

21 Amoh Y, Yang M, Li L, Reynoso J, Bouvet M, Moossa AR, Katsuoka K and Hoffman RM: Nestin-linked green fluorescent protein transgenic nude mouse for imaging human tumor angiogenesis. Cancer Res 65(12): 5352-5357, 2005. PMID: 15958583. DOI: $10.1158 / 0008-5472$.CAN-05-0821

22 Murakami T, Igarashi K, Kawaguchi K, Kiyuna T, Zhang Y, Zhao M, Hiroshima Y, Nelson SD, Dry SM, Li Y, Yanagawa J, Russell 
T, Federman N, Singh A, Elliott I, Matsuyama R, Chishima T, Tanaka K, Endo I, Eilber FC and Hoffman RM: Tumor-targeting Salmonella typhimurium A1-R regresses an osteosarcoma in a patient-derived xenograft model resistant to a molecular-targeting drug. Oncotarget 8(5): 8035-8042, 2017. PMID: 28030831. DOI: 10.18632/oncotarget. 14040

23 Igarashi K, Kawaguchi K, Kiyuna T, Miyake K, Miyake M, Li Y, Nelson SD, Dry SM, Singh AS, Elliott IA, Russell TA, Eckardt MA, Yamamoto N, Hayashi K, Kimura H, Miwa S, Tsuchiya H, Eilber FC and Hoffman RM: Temozolomide combined with irinotecan regresses a cisplatinum-resistant relapsed osteosarcoma in a patient-derived orthotopic xenograft (PDOX) precisiononcology mouse model. Oncotarget 9(8): 7774-7781, 2017. PMID: 29487690. DOI: 10.18632/oncotarget.22892

24 Sun W, Kalen AL, Smith BJ, Cullen JJ and Oberley LW: Enhancing the antitumor activity of adriamycin and ionizing radiation. Cancer Res 69(10): 4294-4300, 2009. PMID: 19401447. DOI: 10.1158/0008-5472.CAN-09-0396

25 Baughn LB, Di Liberto M, Wu K, Toogood PL, Louie T, Gottschalk R, Niesvizky R, Cho H, Ely S, Moore MA and ChenKiang S: A novel orally active small molecule potently induces G1 arrest in primary myeloma cells and prevents tumor growth by specific inhibition of cyclin-dependent kinase 4/6. Cancer Res 66(15): 7661-7667, 2006. PMID: 16885367. DOI: 10.1158/00085472.CAN-06-1098

26 Lane HA, Wood JM, McSheehy PM, Allegrini PR, Boulay A, Brueggen J, Littlewood-Evans A, Maira SM, Martiny-Baron G, Schnell CR, Sini P and O'Reilly T: mTOR inhibitor RAD001 (everolimus) has antiangiogenic/vascular properties distinct from a VEGFR tyrosine kinase inhibitor. Clin Cancer Res 15(5): 1612-1622, 2009. PMID: 19223496. DOI: 10.1158/1078-0432.CCR-08-2057

27 Finn RS, Crown JP, Lang I, Boer K, Bondarenko IM, Kulyk SO, Ettl J, Patel R, Pinter T, Schmidt M, Shparyk Y, Thummala AR, Voytko NL, Fowst C, Huang X, Kim ST, Randolph S and Slamon DJ: The cyclin-dependent kinase $4 / 6$ inhibitor palbociclib in combination with letrozole versus letrozole alone as first-line treatment of oestrogen receptor-positive, HER2-negative, advanced breast cancer (PALOMA-1/TRIO-18): a randomised phase 2 study. Lancet Oncol 16(1): 25-35, 2015. PMID: 25524798. DOI: $10.1016 / \mathrm{S} 1470-2045(14) 71159-3$

28 Yoshida A, Ushiku T, Motoi T, Beppu Y, Fukayama M, Tsuda H and Shibata T: MDM2 and CDK4 immunohistochemical coexpression in high-grade osteosarcoma: correlation with a dedifferentiated subtype. Am J Surg Pathol 36(3): 423-431, 2012. PMID: 22301501. DOI: 10.1097/PAS.0b013e31824230d0

29 Zhou Y, Shen JK, Yu Z, Hornicek FJ, Kan Q and Duan Z: Expression and therapeutic implications of cyclin-dependent kinase 4 (CDK4) in osteosarcoma. Biochim Biophys Acta Mol Basis Dis 1864(5 Pt A): 1573-1582, 2018. PMID: 29452249. DOI: 10.1016/j.bbadis.2018.02.004

$30 \mathrm{Yu}$ Q, Sicinska E, Geng Y, Ahnström M, Zagozdzon A, Kong Y, Gardner H, Kiyokawa H, Harris LN, Stål O and Sicinski P: Requirement for CDK4 kinase function in breast cancer. Cancer Cell 9(1): 23-32, 2006. PMID: 16413469. DOI: 10.1016/ j.ccr.2005.12.012

31 Sheppard KE and McArthur GA: The cell-cycle regulator CDK4: an emerging therapeutic target in melanoma. Clin Cancer Res 19(19): 5320-5328, 2013. PMID: 24089445. DOI: 10.1158/10780432.CCR-13-0259

32 Olmez I, Brenneman B, Xiao A, Serbulea V, Benamar M, Zhang Y, Manigat L, Abbas T, Lee J, Nakano I, Godlewski J, Bronisz A,
Abounader R, Leitinger N and Purow B: Combined CDK4/6 and mTOR inhibition is synergistic against glioblastoma via multiple mechanisms. Clin Cancer Res 23(22): 6958-6968, 2017. PMID: 28814434. DOI: $10.1158 / 1078-0432$.CCR-17-0803

33 Bonelli MA, Digiacomo G, Fumarola C, Alfieri R, Quaini F, Falco A, Madeddu D, La Monica S, Cretella D, Ravelli A, Ulivi P, Tebaldi M, Calistri D, Delmonte A, Ampollini L, Carbognani P, Tiseo M, Cavazzoni A and Petronini PG: Combined inhibition of CDK4/6 and $\mathrm{PI} 3 \mathrm{~K} / \mathrm{AKT} / \mathrm{mTOR}$ pathways induces a synergistic anti-tumor effect in malignant pleural mesothelioma cells. Neoplasia 19(8): 637-648, 2017. PMID: 28704762. DOI: 10.1016/j.neo.2017.05.003

34 Cretella D, Ravelli A, Fumarola C, La Monica S, Digiacomo G, Cavazzoni A, Alfieri R, Biondi A, Generali D, Bonelli M and Petronini PG: The anti-tumor efficacy of CDK4/6 inhibition is enhanced by the combination with PI3K/AKT/mTOR inhibitors through impairment of glucose metabolism in TNBC cells. J Exp Clin Cancer Res 37(1): 72, 2018. PMID: 29587820. DOI: 10.1186/s13046-018-0741-3

35 Law M, Forrester E, Chytil A, Corsino P, Green G, Davis B, Rowe $\mathrm{T}$ and Law B: Rapamycin disrupts cyclin/cyclin-dependent kinase/p21/proliferating cell nuclear antigen complexes and cyclin D1 reverses rapamycin action by stabilizing these complexes. Cancer Res 66(2): 1070-1080, 2006. PMID: 16424043. DOI: 10.1158/0008-5472.CAN-05-1672

36 Higuchi T, Yamamoto J, Sugisawa N, Tashiro Y, Nishino H, Yamamoto N, Hayashi K, Kimura H, Miwa S, Igarashi K, Bouvet M, Singh SR, Tsuchiya H and Hoffman RM: PPAR $\gamma$ Agonist Pioglitazone in Combination With Cisplatinum Arrests a Chemotherapy-resistant Osteosarcoma PDOX Model. Cancer Genomics Proteomics 17(1):35-40, 2020. PMID: 31882549. DOI: 10.21873/cgp.20165

37 Oshiro H, Tome Y, Miyake K, Higuchi T, Sugisawa N, Kanaya F, Nishida K and Hoffman RM: An mTOR and VEGFR inhibitor combination arrests a doxorubicin resistant lung metastatic osteosarcoma in a PDOX mouse model. Sci Rep 11(1):8583, 2021. PMID: 33883561. DOI: 10.1038/s41598-021-87553-9

38 Higuchi T, Sugisawa N, Miyake K, Oshiro H, Yamamoto N, Hayashi K, Kimura H, Miwa S, Igarashi K, Chawla SP, Bouvet M, Singh SR, Tsuchiya $\mathrm{H}$ and Hoffman RM: Sorafenib and Palbociclib Combination Regresses a Cisplatinum-resistant Osteosarcoma in a PDOX Mouse Model. Anticancer Res 39(8):4079-4084, 2019. PMID: 31366491. DOI: 10.21873/anticanres.13565

39 Higuchi T, Sugisawa N, Miyake K, Oshiro H, Yamamoto N, Hayashi K, Kimura H, Miwa S, Igarashi K, Kline Z, Belt P, Chawla SP, Bouvet M, Singh SR, Tsuchiya H and Hoffman RM: Combination Treatment With Sorafenib and Everolimus Regresses a Doxorubicin-resistant Osteosarcoma in a PDOX Mouse Model. Anticancer Res 39(9):4781-4786, 2019. PMID: 31519579. DOI: 10.21873/anticanres.13662

40 Higuchi T, Oshiro H, Miyake K, Sugisawa N, Han Q, Tan Y, Park J, Zhang Z, Razmjooei S, Yamamoto N, Hayashi K, Kimura H, Miwa S, Igarashi K, Bouvet M, Chawla SP, Singh SR, Tsuchiya $\mathrm{H}$ and Hoffman RM: Oral Recombinant Methioninase, Combined With Oral Caffeine and Injected Cisplatinum, Overcome Cisplatinum-Resistance and Regresses Patient-derived Orthotopic Xenograft Model of Osteosarcoma. Anticancer Res 39(9):46534657, 2019. PMID: 31519563. DOI: 10.21873/anticanres.13646

Received April 22, 2021

Revised May 28, 2021

Accepted June 1, 2021 